\title{
Advances in impact resistance testing for explosion-proof electrical equipment
}

\author{
Vlad Mihai Pasculescu ${ }^{1,}$, Nicolae Ioan Vlasin ${ }^{1}$, Gheorghe Daniel Florea ${ }^{1}$, Marius Cornel \\ Suvar ${ }^{1}$, and Cosmin Ioan Colda ${ }^{1}$ \\ ${ }^{1}$ National Institute for Research and Development in Mine Safety and Protection to Explosion - \\ INSEMEX, 32-34 G-ral Vasile Milea Street, 332047, Petroșani, Hunedoara County, Romania
}

\begin{abstract}
The design, construction and exploitation of electrical equipment intended to be used in potentially explosive atmospheres presents a series of difficulties. Therefore, the approach of these phases requires special attention concerning technical, financial and occupational health and safety aspects. In order for them not to generate an ignition source for the explosive atmosphere, such equipment have to be subjected to a series of type tests aiming to decrease the explosion risk in technological installations which operate in potentially explosive atmospheres. Explosion protection being a concern of researchers and authorities worldwide, testing and certification of explosion-proof electrical equipment, required for their conformity assessment, are extremely important, taking into account the unexpected explosion hazard due to potentially explosive atmospheres, risk which has to be minimized in order to ensure the occupational health and safety of workers, for preventing material losses and for decreasing the environmental pollution. Besides others, one of the type tests, which shall be applied, for explosionproof electrical equipment is the impact resistance test, described in detail in EN 60079 which specifies the general requirements for construction, testing and marking of electrical equipment and Ex components intended for use in explosive atmospheres. This paper presents an analysis on the requirements of the impact resistance test for explosion-proof electrical equipment and on the possibilities to improve this type of test, by making use of modern computer simulation tools based on finite element analysis, techniques which are widely used nowadays in the industry and for research purposes.
\end{abstract}

\section{Introduction}

The explosion risk is one of the main industrial hazards from the economy, this risk being present in all units which produce, process, manipulate, store or transport hazardous substances, respectively products with flammable and explosive characteristics. Explosion protection is of high importance for the occupational health and safety field, explosions endangering the life and health of workers due to their resulting flames and gas pressures,

" Corresponding author: vlad.pasculescu@insemex.ro 
to the presence of hazardous products and to the consumption of oxygen from the atmospheric air. [1-2]

In the protection to explosion field, within the Romanian legislation have been transposed the two European Directives, the so called "ATEX" Directives, which regulate the placing on the European market of products intended to be used in potentially explosive atmospheres, respectively their usage in safety conditions.

Starting from April 20 $0^{\text {th }}$ 2016, the new ATEX Directive 2014/34/EU of the European Parliament and of the Council of 26 February 2014 on the harmonisation of the laws of the Member States relating to equipment and protective systems intended for use in potentially explosive atmospheres (recast) has entered in force, substantially amending and replacing Directive 94/9/EC.

The ATEX "Workplace" Directive 1999/92/EC which deals with the minimum requirements for improving the level of health and safety protection of workers potentially at risk from explosive atmospheres complements the responsibilities of manufacturers under Directive 2014/34/EU by setting out the responsibilities of employers.

For the authorities of the Member States to trust in the products which are placed on the community market are required guarantees on the products' conformity within a system of mutual recognition of normative requirements. A high safety level in areas with explosion hazard may be guaranteed only through an efficient and close cooperation between all parties involved: manufacturers, certification bodies, authorities, end-users of equipment, as well as persons who install equipment within the installations. [3-4]

Placing on the market and/or into operation of Ex products (Ex equipment, protective systems and devices) is allowed only if they do not harm the health and safety of persons, or, if the case, of domestic animals or goods, when they are properly installed, maintained and used in accordance with their destination. For these conditions to be fulfilled, Ex equipment, protective systems and safety devices have to comply with the essential health and safety requirements (EHSR) which are applicable for their intended destination. [5-8]

\section{Impact resistance testing for explosion-proof electrical equipment}

Electrical equipment used in potentially explosive atmospheres may represent an ignition source for such atmospheres. In order to decrease this risk, it has been established that they have to be subject to type tests in order to establish if they are compliant to be used in explosive atmospheres [9].

One of these tests is the impact resistance test. Therefore, in accordance with Standard EN 60079-0, Explosive atmospheres - Part 0: Equipment - General requirements, the electrical equipment gas to be subjected to the effect of a $1 \mathrm{~kg}$ weight test mass falling (Fig. 2) from a specific height $h$. The height $h$ is specified in the standard in relation with the destination of the electrical equipment and is presented in Table 1.

Table 1. Tests for resistance to impact

\begin{tabular}{|c|c|c|c|c|}
\hline & \multicolumn{4}{|c|}{$\begin{array}{c}\text { Drop height } h \text { with } 1 \mathrm{~kg} \text { mass } \\
\mathrm{m}\end{array}$} \\
\hline Equipment grouping & \multicolumn{2}{|c|}{ Group I } & \multicolumn{2}{|c|}{ Group II } \\
\hline Risk of mechanical danger & High & Low & High & Low \\
\hline $\begin{array}{l}\text { a) Enclosures and external accessible parts of enclosures } \\
\text { (other than light-transmitting parts) }\end{array}$ & 2 & 0,7 & 0,7 & 0,4 \\
\hline b) Guards, protective covers, fan hoods, cable glands & 2 & 0,7 & 0,7 & 0,4 \\
\hline Light-transmitting parts without guards & 0,7 & 0,4 & 0,4 & 0,2 \\
\hline d) Light-transmitting parts with guard having individual & 0,4 & 0,2 & 0,2 & 0,1 \\
\hline
\end{tabular}




\begin{tabular}{|l|l|l|l|}
\hline & \multicolumn{3}{|c|}{ Drop height $\boldsymbol{h}$ with 1 kg mass } \\
\hline openings from $625 \mathrm{~mm}^{2}$ to $2500 \mathrm{~mm}^{2}$ & & & \\
\hline $\begin{array}{l}\text { NOTE A guard for light-transmitting parts having individual openings from } 625 \mathrm{~mm}^{2} \text { to } 2500 \mathrm{~mm}^{2} \\
\text { reduces the risk of impact, but does not prevent impact }\end{array}$ \\
\hline
\end{tabular}

The test mass has to be fitted with an impact head made of steel, of semi-spherical shape, having $25 \mathrm{~mm}$ in diameter.

Before each test, there shall be verified of the surface of the impact head is in good shape.

The impact resistance test has to be performed on the completely assembled and ready for use electrical equipment; however, if this is not possible (i.e. light-transmitting parts), the test has to be performed on the un-mounted relevant parts, but which are fixed in their mounting support or in an equivalent one. Tests upon an empty enclosure are allowed only with a proper justification provided in the documentation.

The impact points have to be the places which are considered to be the weakest and they have to be external parts which might be exposed to impact. If the enclosure is protected by another enclosure, only the external parts of the assembly have to be subjected to impact resistance tests.

The electrical equipment must be mounted on a steel base, in such a way that the impact direction to be perpendicular to the surface to be tested if this is a flat one, or perpendicular to the tangent to the surface at the point of impact, if it is not a flat one. The pedestal must have a mass of at least $20 \mathrm{~kg}$ or to be rigidly fixed to or recessed in the floor, for example, set in concrete. Figure 1 shows an example of a stand used for performing the impact resistance tests for electrical equipment, being schematically presented in Figure 3.

The impact resistance test has to be performed at least for two specimens. For lighttransmitting parts made of glass, the test has to be performed only once for each specimen. In any other case, the impact resistance test has to be performed in two separate places on each specimen. [10]

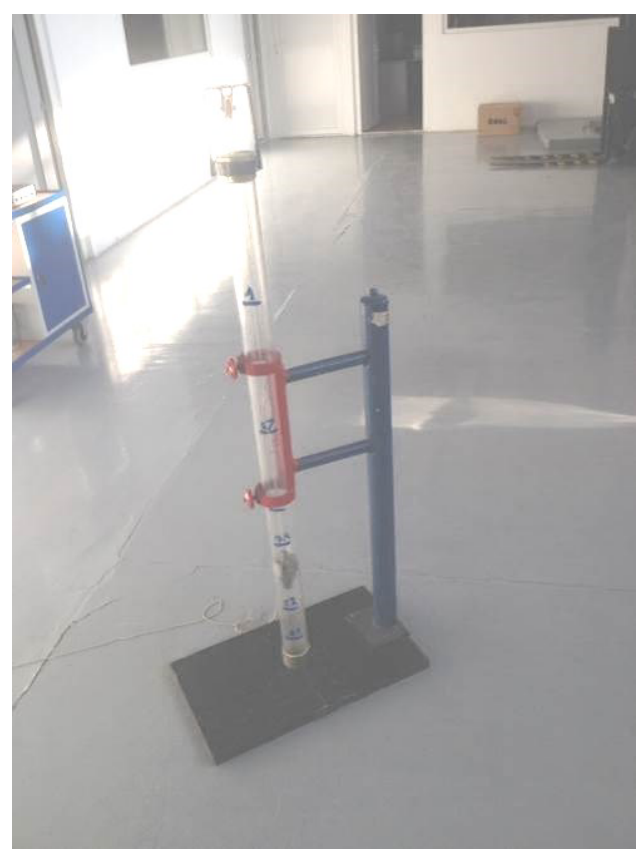

Fig. 1. Stand for impact resistance testing 


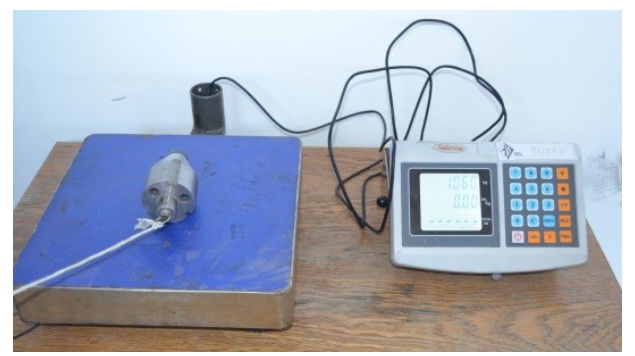

Fig. 2. $1 \mathrm{~kg}$ steel mass.

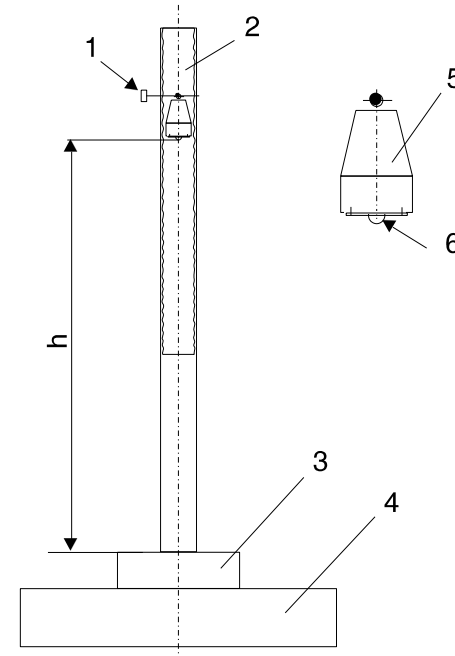

Legend:

$6 \quad 1$ Adjustment pin

2 Guidance tube made of plastic

3 Equipment to be tested

4 Steel base (mass $\geq 20 \mathrm{~kg}$ )

5 Steel mass $-1 \mathrm{~kg}$

6 Impact head, $25 \mathrm{~mm}$ in diameter,

made of hardened steel

$\mathrm{h}$ Falling height

Fig. 3. Representation of the impact resistance-testing stand

\section{Quantitative tests for determining the impact resistance of explosion-proof electrical equipment}

Normally, the impact resistance test does not provide a value as result, the result being only qualitative, namely the equipment "passed" or "did not pass" the test.

In order to be able to record the load on the equipment generated from the falling test mass, the impact resistance test stand has been equipped with a $50 \mathrm{kN}$ tension load cell force transducer (Fig. 4) and the values has been recorded using MaxTest software.

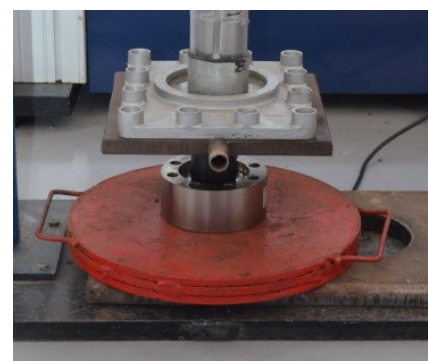

Fig. 4. $50 \mathrm{kN}$ tension load cell force transducer 
There have been subjected to the impact resistance test several equipment in Group II (Fig. 5-9), with different types of protection to explosion, for different falling heights of the test mass, in accordance with the type of equipment and the mechanical danger risk. MaxTest software generated the load-time graphs for each test, these being presented in Fig. 10.
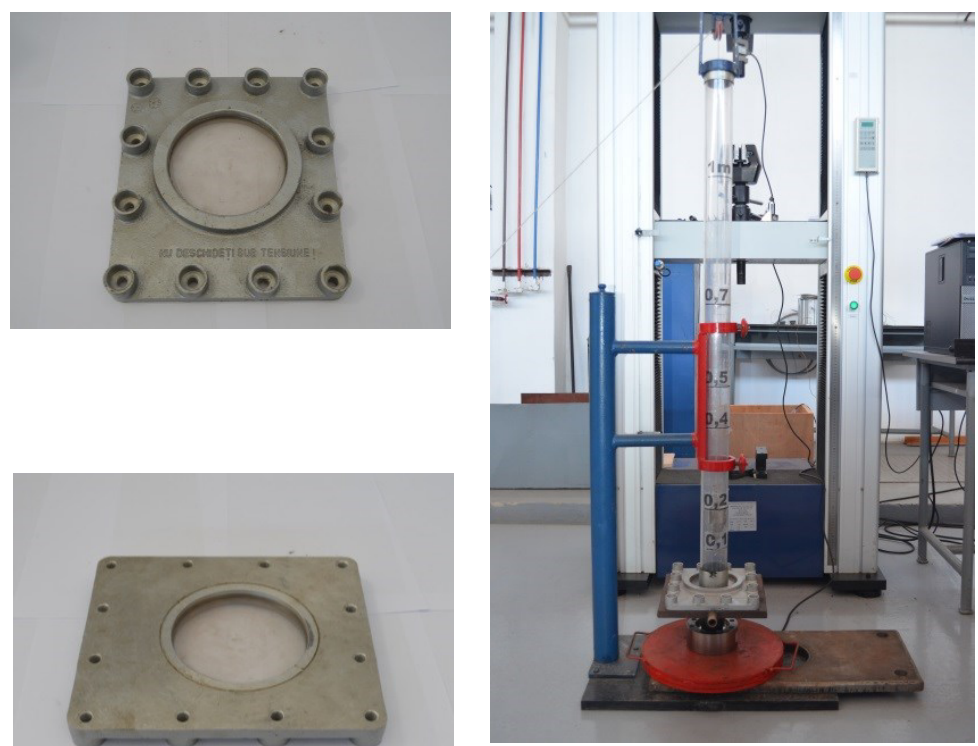

Fig. 5. Impact resistance test carried out for equipment no. 1
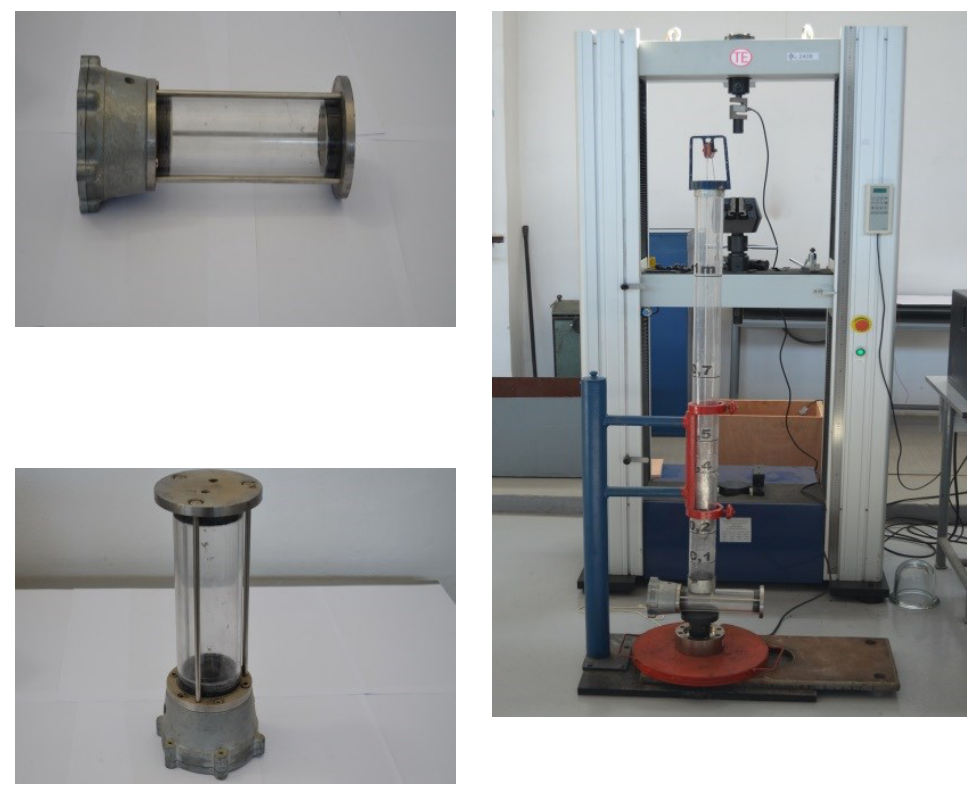

Fig. 6. Impact resistance test carried out for equipment no. 2 

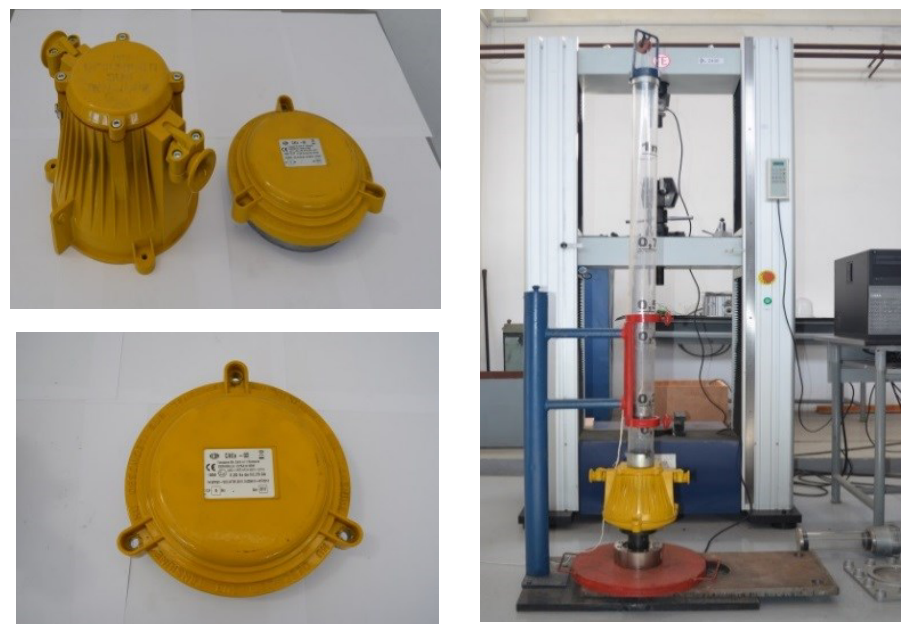

Fig. 7. Impact resistance test carried out for equipment no. 3
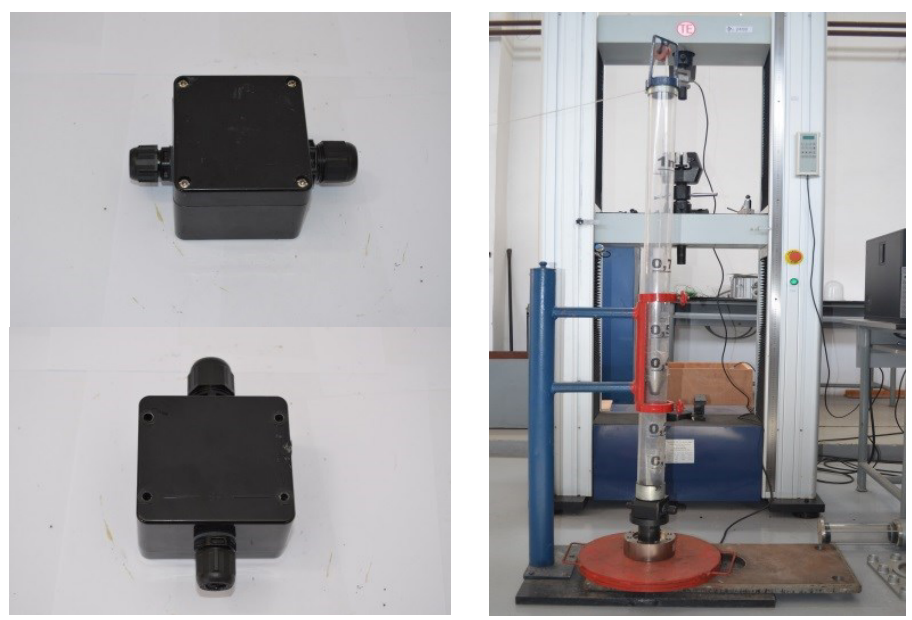

Fig. 8. Impact resistance test carried out for equipment no. 4
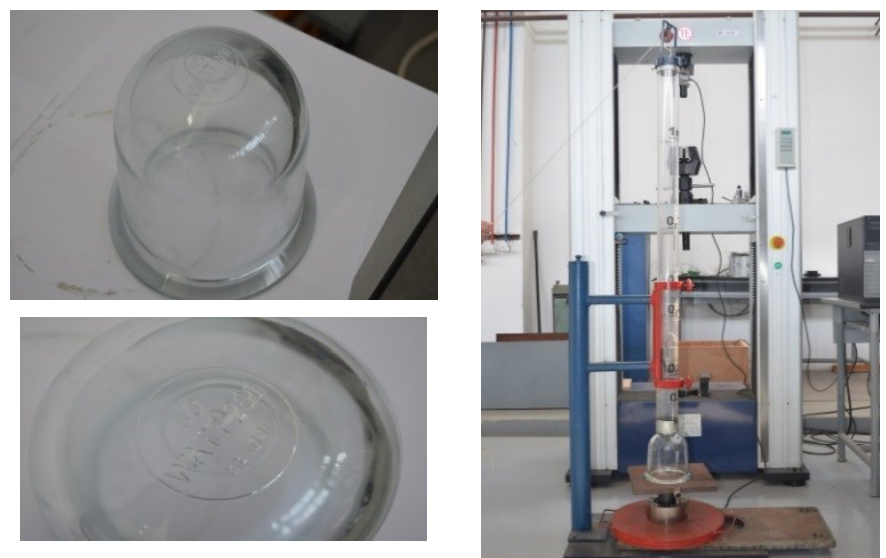

Fig. 9. Impact resistance test carried out for equipment no. 5 . 

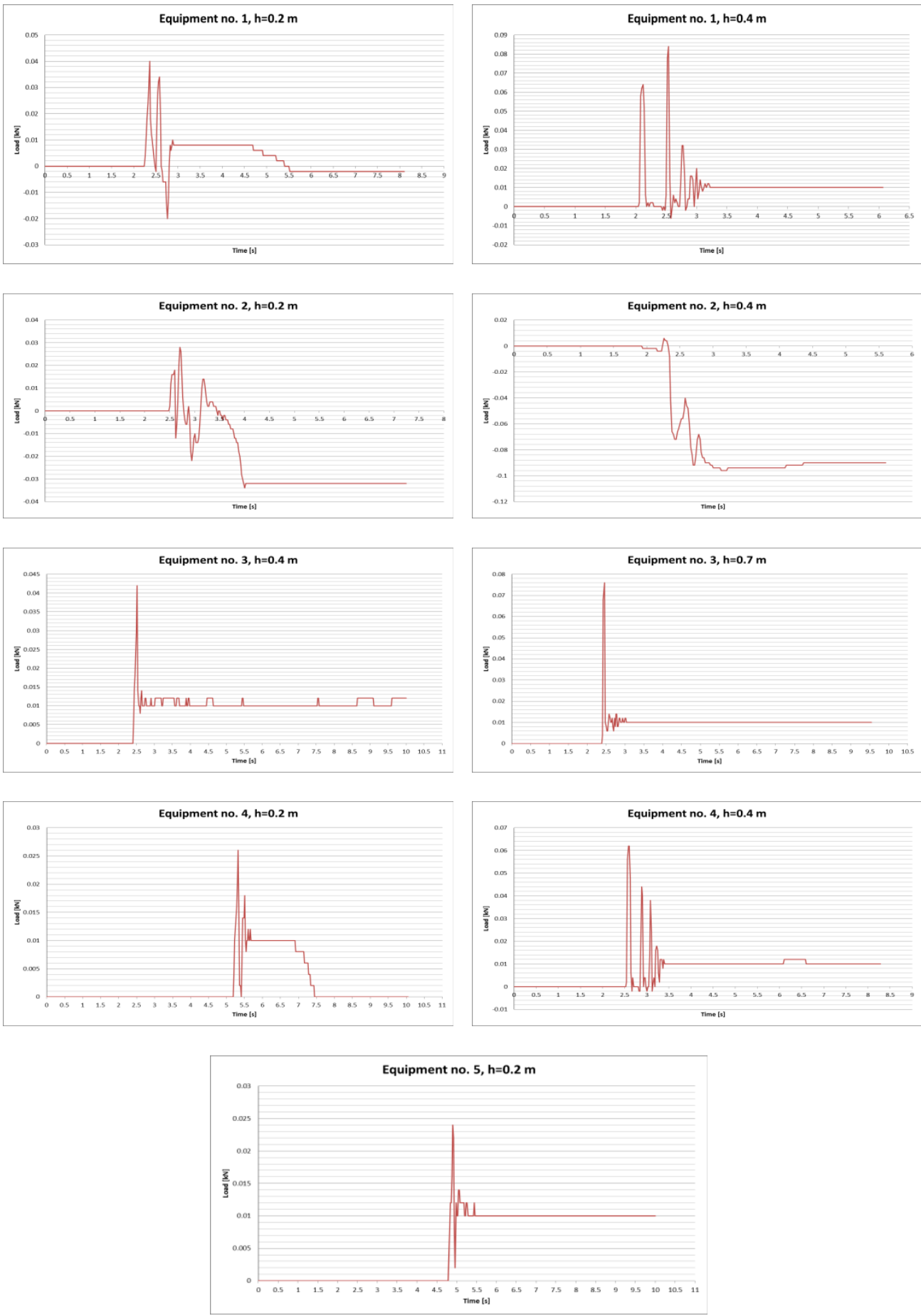

Fig. 10. Load-time graphs for the equipment subjected to impact tests 


\section{Conclusions}

Results obtained and presented in the paper are going to be analysed in order to calibrate the computational simulation tools of which INSEMEX disposes on the tests for impact resistance of explosion-proof electrical equipment. It has been established in previous studies that ANSYS Structural represents the best solution for performing the computational simulations for impact resistance tests, the results obtained are going to be used as input data for these simulations, using geometries which describe as close as possible the types of equipment tested. [10-12]

Therefore, the currently known methods for impact resistance tests for explosion-proof electrical equipment are going to be improved by using modern computational simulation techniques, resulting in an improved occupational health and safety level for industries which process, transport, store etc. flammable substances and in which there is the possibility for an explosive atmosphere to occur.

This paper was developed within the Nucleu-Programme, carried out with the support of ANCSI, project no. PN-16-43-03-06

\section{References}

1. R.I. Moraru, G.B. Babut, L.I. Cioca, Environ Eng Manag J, 13 (6), 1371-1376 (2014)

2. V. Torretta, E. Rada, M. Ragazzi, E. Trulli, I.A. Istrate, L.I. Cioca, Waste Manage, 45, 152-160 (2015)

3. L.I. Cioca, R.I. Moraru, Arch Min Sci, 57 (1), 53-60 (2012)

4. I. Ivascu, L.I. Cioca, Advances in Education Research, 49, 77-90 (2014)

5. D. Pasculescu, L. Lupu, V. Pasculescu, I. Inisconi, M. Suvar, Environ Eng Manag J, 11 (7), 1267-1271 (2012)

6. D.C. Petrilean, S.I. Irimie, V. Baleanu, S. Stanila, Environ Eng Manag J, 13 (6), 1383-1388 (2014)

7. G. Buica, A.E. Antonov, C. Beiu, I. Iorga, Environ Eng Manag J, 11 (7), 1247-1255 (2012)

8. M. Prodan, E. Ghicioi, D. Oancea, Environ Eng Manag J, 13 (6), 1409-1414 (2014)

9. M. Magyari, S. Burian, L. Moldovan, D. Fotau, C. Colda, Proceedings of the 15th International Multidisciplinary Scientific GeoConference, 1 (1), 835-842 (2015)

10. V.M. Pasculescu, G.D. Pricop, M.S. Morar, V. Florea, Proceedings of the 15th International Multidisciplinary Scientific GeoConference SGEM, 1 (2), 291-298 (2015)

11. D.G. Pricop, V.A. Florea, Proceedings of the 15th International Multidisciplinary Scientific GeoConference SGEM, 1 (1), 697-704 (2015)

12. D. Pasculescu, T. Niculescu, Proceedings of the 15th International Multidisciplinary Scientific GeoConference SGEM, 1 (2), 323-330, (2015) 